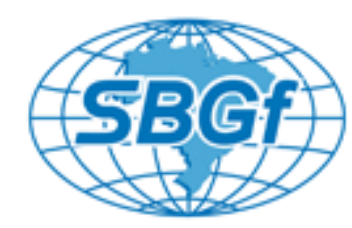

\title{
Reducing subsurface uncertainties with MAZ imaging in pre-salt Santos Basin
}

\author{
Pedro Barros, Zhao Ge, Hongyan Li, Carina Lansky, Marcela Ortin and Raul Ysaccis, Schlumberger
}

\begin{abstract}
Copyright 2021, SBGf - Sociedade Brasileira de Geofísica
This paper was prepared for presentation during the $17^{\text {th }}$ International Congress of the Brazilian Geophysical Society held in Rio de Janeiro, Brazil, 16-19 August 2021.

Contents of this paper were reviewed by the Technical Committee of the $17^{\text {th }}$ International Congress of the Brazilian Geophysical Society and do not necessarily represent any position of the SBGf, its officers or members. Electronic reproduction or storage of any part of this paper for commercial purposes without the written consent of the Brazilian Geophysical Society is prohibited.
\end{abstract}

\begin{abstract}
Huge volumes of reserves and the high productivity of the Santos pre-salt reservoirs have sparked the interest of major oil companies. However, this prolific play has significant subsurface challenges (e.g., volcanic presence, evaporite thickness variation, narrow mini basins bounded by steep-sided salt diapirs, small salt overhangs, reservoir heterogeneity, etc.) that must be addressed to improve the exploration-to-production cycle. In this study, it is discussed how the upgrade achieved by a multi azimuth (MAZ) reimaging in Central Santos basin can help in defining a more confident plan for the exploration and appraisal of the area, as it enables a better understanding of this complex geological setting.
\end{abstract}

Many uncertainties in the Santos Basin pre-salt are due to the inadequate quality of the available seismic image. Most of the seismic surveys already acquired in the region are narrow azimuth (NAZ) surveys. They therefore lack the illumination of target reflectors, and the robustness required for the velocity model building algorithms. This is especially the case in complex salt bodies.

The pre-salt seismic imaging is mainly affected by the illumination, the accuracy of the velocity model, the low frequency reflections, and noise content of the final migrations. We show that these geophysical aspects can be optimized with the reprocessing of multiple NAZ surveys in the central portion of the basin, by applying velocity model building processing that combines multi-azimuth common image point (CIP) tomography, conventional and reflection based full-waveform inversions (FWI), and scenario interpretation of the salt layer in complex areas.

Following this systematic approach, the resulting MAZ surveys show a dramatic improvement of the pre-salt image. From these data, we can make a more confident interpretation of the different pre-salt seismic sequences; e.g., the lower rift, upper rift, and sag sequences. Facies variations related to the main carbonate reservoirs in the sag sequence can be better defined in the MAZ data due to the upgrade on the seismic reflection continuity, resolution and amplitude response.

Also, the enhanced seismic image of the MAZ surveys shows a better delineation of the pre-salt faults. It helps to obtain a more detailed interpretation of the structural framework and provides a better idea for any compartmentalization of the pre-salt discoveries.

In short, for Central Santos Basin, the MAZ reimaging provides a significant image uplift when compared to the NAZ legacy images, and this new dataset can be essential to improve the interpretation of the structural and stratigraphic framework for the pre-salt play.

\section{Introduction}

The Santos Basin is located in the southeastern Brazilian continental margin and has an area of approximately $350,000 \mathrm{~km} 2$. Since early 2000 , the Santos Basin became well known for hydrocarbon exploration in its huge pre-salt oil and gas fields. Prospecting of these plays have to overcome the following challenges: Santos basin has an average water depth of $2 \mathrm{~km}$, a thick layer of stratified evaporites, and major pre-salt reservoirs beneath, with extensive faults. The post-salt province is often embedded with carbonates and volcanic layers with abnormally high velocity. All these complexities, in combination, have proven to be great challenges to conventional acquisition approaches and seismic processing methods.

The tectono-stratigraphic evolution in Santos Basin is categorized into three mega-sequences resulting from early rifting and subsequent drifting phases between the South American and African plates (Mohriak and Fainstein, 2012). Aptian rift phase was preceded by the extrusion of basaltic lavas that overlie an igneous metamorphic basement and constitute the Camboriu Formation (Moreira et al., 2007). This rift is characterized by half-graben structures filled in the lowermost part by the basalts (Chang et al., 2008) and then followed by fluvial and lacustrine sediments of the Guaratiba Group (Meisling et al., 2001; Modica and Brush, 2004; Moreira et al., 2007; Rodriguez et al., 2017). Lacustrine shale source rock with $2 \%$ to $6 \%$ organic content was deposited during the final stage of the rift. (Fernandez, 2017). Coquina facies formed in the uppermost is part of the main reservoirs of the pre-salt play. An Aptian to Early Albian post-rift phase comprises the Barra Velha and the Ariri Formations ranging from continental to shallow marine (Moreira et al., 2007). The Barra Velha Formation consists of microbial carbonates in proximal depositional settings and shales. The Ariri Formation is an evaporite-rich succession characterized by multiple marine incursions and basin desiccation (Jackson et al., 2014; Rodriguez et al., 2017). The non-marine 
Reducing uncertainties with MAZ imaging in pre-salt Santos Basin carbonate is the main pre-salt reservoir and the overlying evaporites are the main seal. The Albian to present drift phase is characterized by thermal subsidence and open marine conditions. The marine drift mega-sequence may be subdivided into two sequences: shallow marine platform carbonate deposits during the Albian (Guaruja Formation) and deep-marine clastic-dominated deposits from Cenomanian to present (i.e., Itanhaem to Marambaia Formation) (Modica and Brush, 2004; Moreira et al., 2007; Rodriguez et al., 2017). Most Santos post-salt discoveries occur in deep-marine turbidite reservoirs.

Considering this geology, the creation of a well-suited velocity model that generates an image that reduces the uncertainty of the exploration and production activities has presented several challenges. A legacy narrow azimuth (NAZ) survey data processing project faced several barriers that could not be fully transposed. Two of the main reasons for this are: lack of illumination at pre-salt horizons where the salt geometry becomes complex, hindering the results from CIP tomography, and short offsets that do not record the refraction energy below the top of the evaporites. This this limits the effectiveness of the standard FWI. This acquisition geometry is vastly the most common in the basin. Due to cost, time and environmental factors, the acquisition of alternatives is not always possible.

Le Diagon et al. (2017) has demonstrated based on seismic modelling the advantages of adding azimuthal coverage when imaging the pre-salt targets in the Santos basin. Additionally, Ortin et al. (2020) showed how combining ray paths of different NAZ surveys affects the general processing results using the Central Santos datasets that are in use here.

The Central Santos MAZ Reimaging project uses a combination of three NAZ surveys and one FAZ survey as input. The main survey is oriented northwest to southeast with a 123 degrees azimuth - used in the legacy processing presented here for comparison. The second NAZ survey has a similar orientation with 158 degrees azimuth while the third NAZ survey has an east-west orientation. The FAZ survey is a single coil acquisition done in 2011 (Le Diagon, 2011).

In this study, we present the velocity model building case study of the combination of multiple legacy NAZ acquisition using a combination of different velocity update algorithms with well information and evaluate the effects of the new product in the work of delimitation and evaluation of presalt reservoirs.

\section{Method}

A legacy model from the processing of the main underlying survey was used as base for velocity model building of the post-salt layer. This velocity model was smoothed, and the anisotropy was recalibrated to match the existing well data.

The first CIP tomography (Woodward et al., 2008) iteration and the first LS FWI (Maximum frequency of $9 \mathrm{~Hz}$ ) were performed using one azimuth only. These processes targeted the longer wavelength updates. As more details were added to the post-salt sediment model the other surveys were added to the second FWI pass using the maximum frequency of $12 \mathrm{~Hz}$ and to the final post-salt sediment CIP tomography passes. Sediment model analysis suggests layers of post-salt carbonate and volcanic intrusions with abnormally high velocity. Regional surfaces such as Top of Albian Carbonate (TOC) and Top of Evaporites (TOS) identifying such layers are interpreted. These interpretations and well markers of both TOC and TOS were used to access the results of each iteration and, when required, explicit constraints in the tomographic inversion.

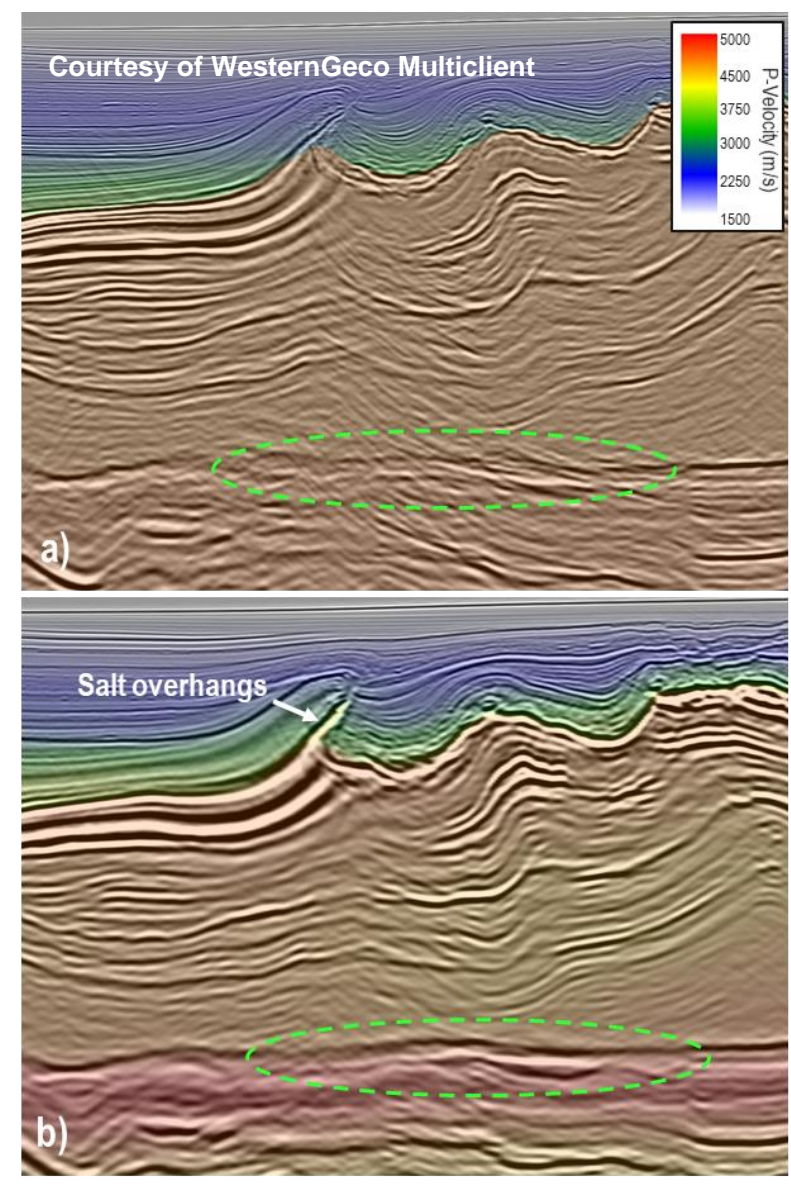

Figure 1 - Seismic section with velocity model overlaid. a) Single azimuth legacy model and image; b) Final MAZ image with velocity model, including salt overhangs

With the post-salt sediment velocity model finalized, the TOS was interpreted at a fine scale. The evaporites canopy in Santos Basin has a depth of $3 \mathrm{~km}$ to $5 \mathrm{~m}$. They are well known for their stratified and deformed halite layers, formed by the multiple marine incursions and basin desiccation. They are also characterized by a very rugose top, usually coupled with deep sediment mini basins and carbonate rich geobodies, as described earlier. Complex structures at this depth are identified and different geometries were tested to evaluate the options with the best image at pre-salt level. These structures included thin extrusion of the evaporite body creating small scale overhangs. (Figure 1)

The initial evaporite velocity model was created by splitting the layer into two different zones according to its internal reflectivity. The first zone was related to the presence of 
P. Barros, Z. Ge, H. Li, C. Lanski, M. Ortin and R.Ysaccis several bedded reflections. This correlates to the presence of heterogenous salt lithologies, such as intercalation of anhydrites, halites, tachydrates, etc. A smoothed version of the legacy velocity model was used in this zone. The second evaporite zone was defined by the absence of internal reflections within a relatively large zone, indicating the overwhelming presence of halite. The model of this layer consists of a single velocity estimated from the average of the measurements of sonic profiling available in the area. The division of the two zones was defined by a smoothed sweetness attribute, which corresponds to the ratio between the amplitude envelope and the square root of the measured instant frequency. Higher sweetness values indicate a bigger occurrence of coherent reflections and therefore indicate the stratified evaporites.

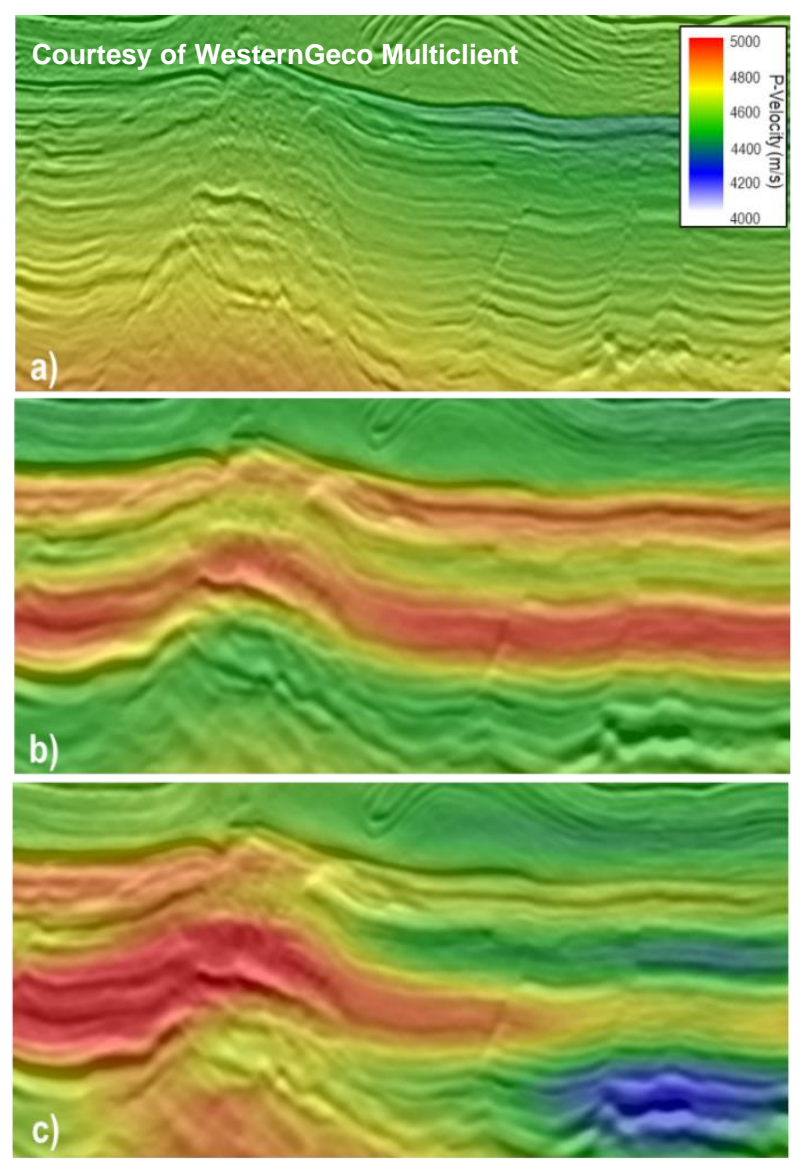

Figure 2 - Pre-salt velocity model results: a) Legacy velocity model; b) Initial model derived from sonic logs and interpretation; c) Final model after multi-azimuth RFWI and CIP tomography

Moreira et al (2007) and pre-salt model analysis indicates strong velocity elevation in the layer immediately underneath BOS down to Lower Synrift, but have rather smoothed velocity slowdown downward. To build a model reflecting this contrast in depth, we interpret several presalt surfaces to identify geological trending in detail. Lower Syn Rift and basement are defined to separate the stratigraphic zones in this region. Very vertically stretched faults have been observed, which prevent the automatic tracking tool to function efficiently on these surfaces. These horizons were used to extrapolate the $1 \mathrm{D}$ velocity trend designed by estimating the smoothed velocity trend from the available sonic logs. In order to account for the maximum depths recorded in some wells, the model analysis information mentioned earlier was used to include a general slower seismic velocity in this region, until reaching the basalts and the basement, where a smooth increase was added. (Figure 2b).

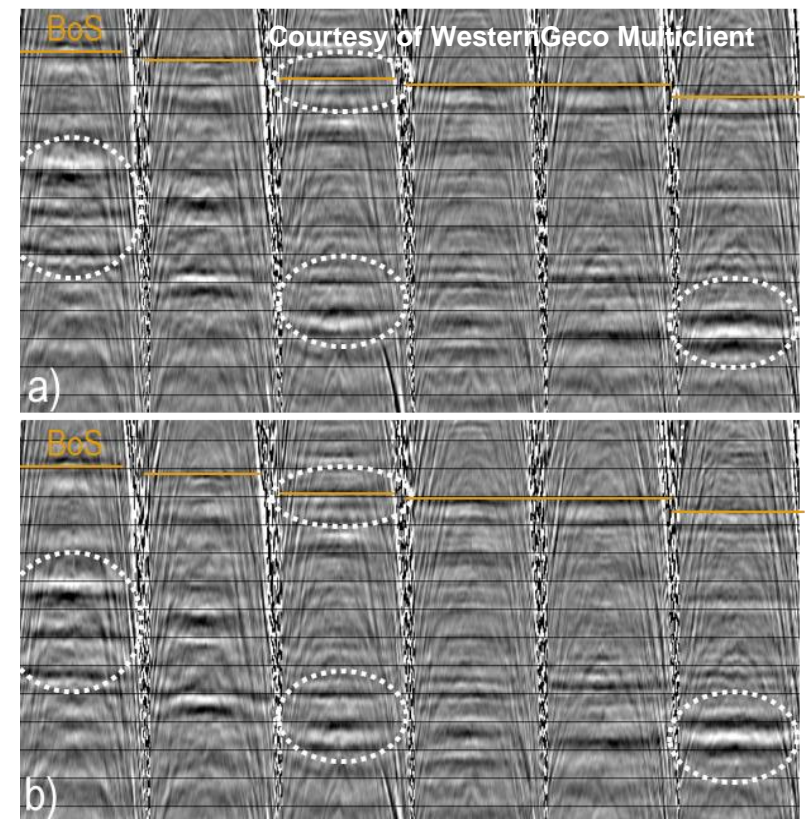

Figure 3 - KDM CIP gather of two azimuths (63o to left and 1230 to the right) migrated with: a) Legacy salt and pre-salt velocity model; b) Final model after multiazimuth RFWI and CIP tomography

The velocity updates in the intra-salt and pre-salt layers were done by combining a reflection FWI (RFWI) and CIP tomography. In both cases, multiple azimuths were used as inputs to the processes These surfaces were also updated constantly and interactively with the tomography and RFWI update throughout the model building.

The RFWI was introduced by Sun et al. (2016). It uses the reflected energy recorded in the data to include in the forward model using born modelling and travel-time based objective function to generate a low-wavenumber update that goes deeper than the available refraction energy recorded.

Finally, a CIP tomography was run using the combination of all the NAZ surveys in both Kirchhoff depth migration (KDM) and RTM subsurface azimuth angle gathers (SAAGs) (Vyas et al., 2011) to pick the residuals and perform a weighted inversion. The use of both migration algorithms allows for a more reliable event reconstruction of the pre-salt that is permitted by the RTM, while using higher frequencies for the intra-salt picks with the KDM. As done previously, the base of salt reflection was weighted to drive the overall salt update and achieved a better well correlation. Figure 2 shows the resulting model of the new 
Reducing uncertainties with MAZ imaging in pre-salt Santos Basin initial model created and the result of the pre-salt model building compared to the legacy model.

The datasets of all the surveys used in the final migrations were fully reprocessed. This processing included more contemporary noise attenuation techniques, enhancement of broadband frequency content with adaptive deghosting (Rickett 2014), and 3D-SRME using all the azimuths for multiple prediction. This was combined with variable aperture definition based on ray-tracing of the main reflections (Espinoza et al., 2017).

The final images were created with input data after the full broadband processing flow. They were migrated with a $\mathrm{KDM}$ and an RTM at $45 \mathrm{~Hz}$ maximum frequency. Each survey was migrated separately and later combined during the image enhancement.

\section{Results}

The resulting velocity models are presented in Figure 2 . The comparison reveals that the initial model for the presalt better conformed to the structures, while the CIP tomography and RFWI updates captured the local variations of lithology. This introduced a faster velocity in the structural high and a slower velocity in the low.

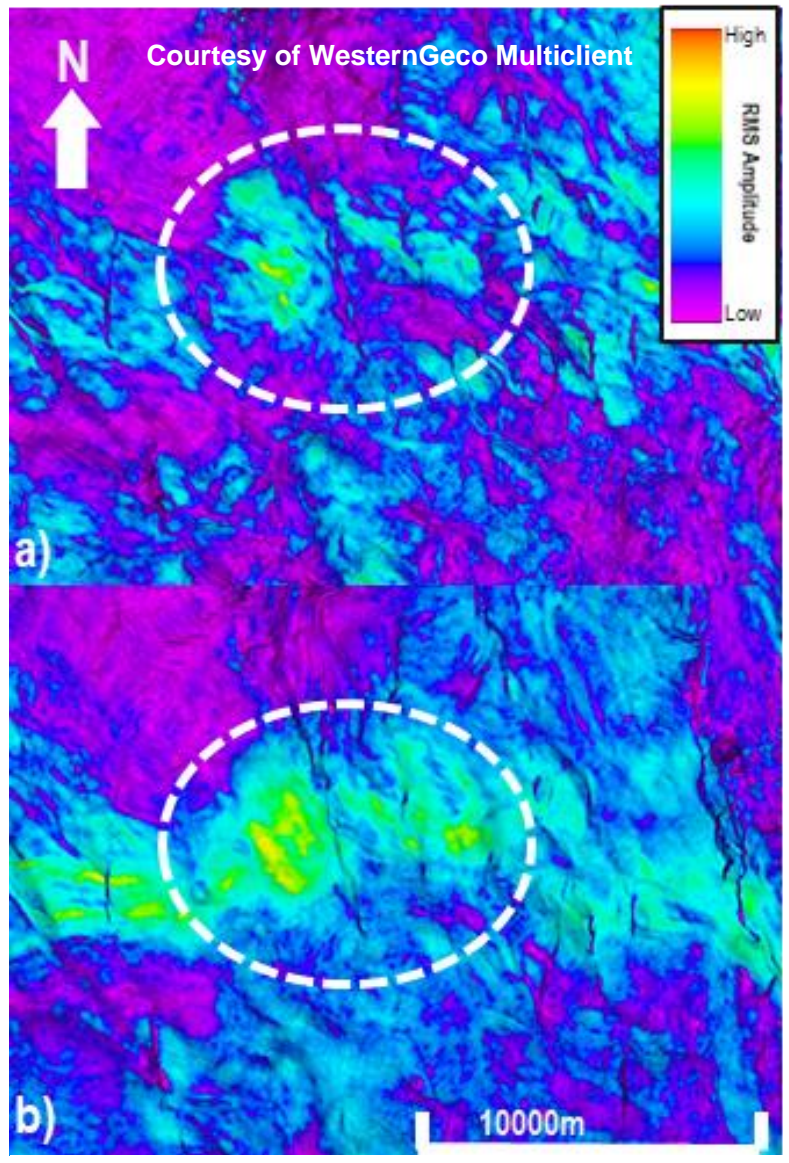

Figure 4 - Normalized RMS amplitude measured at base of salt on: a) legacy single azimuth image; b) final multiazimuth processing image
The salt overhangs are usually thin (less than $100 \mathrm{~m}$ in diameter), tilted, and can extend few hundred meters laterally. The effects of inclusion of the salt overhangs and the addition of different azimuths are pointed out in the green circle of Figure 1. It is apparent that the reflection at base of salt and pre-salt become more coherent while the migration swings are eliminated. Figure 3 shows how the legacy and final velocity models satisfy the moveout seen on the multiple azimuth data. Here, a mild improvement can be seen especially at the circled reflectors.

As shown in Figure 4, RMS amplitude indicates a better coherence in the amplitude response for the BOS seismic event in the MAZ compared to the legacy NAZ data. Also, NW-SE normal faults in the pre-salt section are much easier to identify in the MAZ data.

With the use of multi-azimuth migration, modeling, and interpretation, intra-salt, base of salt and pre-salt interfaces are better illuminated, and we can see a more continuous reflector for the BOS, as swings are significantly attenuated. Thus, auto tracking based on image coherence on BOS interpretation works more efficiently with higher confidence in the latest migration, as shown in Figure 5.

In Figure 6, highlighted in blue is a carbonate mound generated at a structural high that was not visible in the legacy single azimuth image. This structural feature may become a primary exploration opportunity. Additionally, the attribute volume of amplitudes technic (tecVA) (Bulhões \& Amorin, 2005) highlighted in green shows that the new processing presents a higher definition of the pre-salt package, mainly between the base of evaporites and in the upper rift zone. The same figure shows that the lower frequency and multi-azimuth illumination makes the fault system inside the orange circle to now be visible.

\section{Conclusions}

For the central Santos Basin, the MAZ reprocessing provides a significant image uplift when compared to the NAZ legacy images. This new MAZ dataset can be crucial in obtaining a better understanding of the stratigraphic and structural framework of the pre-salt play, and thereby enabling optimization of the exploration and appraisal plans in the area.

The combination of different FWI algorithms and tomographic updates using multiple azimuth data leads to a more accurate velocity model that has more data correspondence and geological correlation when compared to the legacy single azimuth processing.

The additional tested salt bodies combined with different ray path azimuths are important to reduce the migration noise and enhance the reflection response of the base of salt and pre-salt layers.

The improved signal-to-noise ratio of the data input to migration, a more detailed and geologically conformable velocity model, and the multiple azimuths were essential in obtaining a more consistent amplitude range and a better illumination for the pre-salt section. This improved data quality can facilitate more efficient interpretation, especially for the primary reservoirs within the pre-salt sag sequence. 
P. Barros, Z. Ge, H. Li, C. Lanski, M. Ortin and R.Ysaccis In summary, the results shown by the merge of multiple reprocessed surveys with different azimuths show the viability of this type of project to enhance the pre-salt seismic image of the central Santos Basin. A final $45 \mathrm{~Hz}$ RTM MAZ survey shows an improved resolution of the carbonate reservoirs as well as a better delineation of the fault planes in the pre-salt section. This helps reduce the uncertainties of the seismic interpretation.
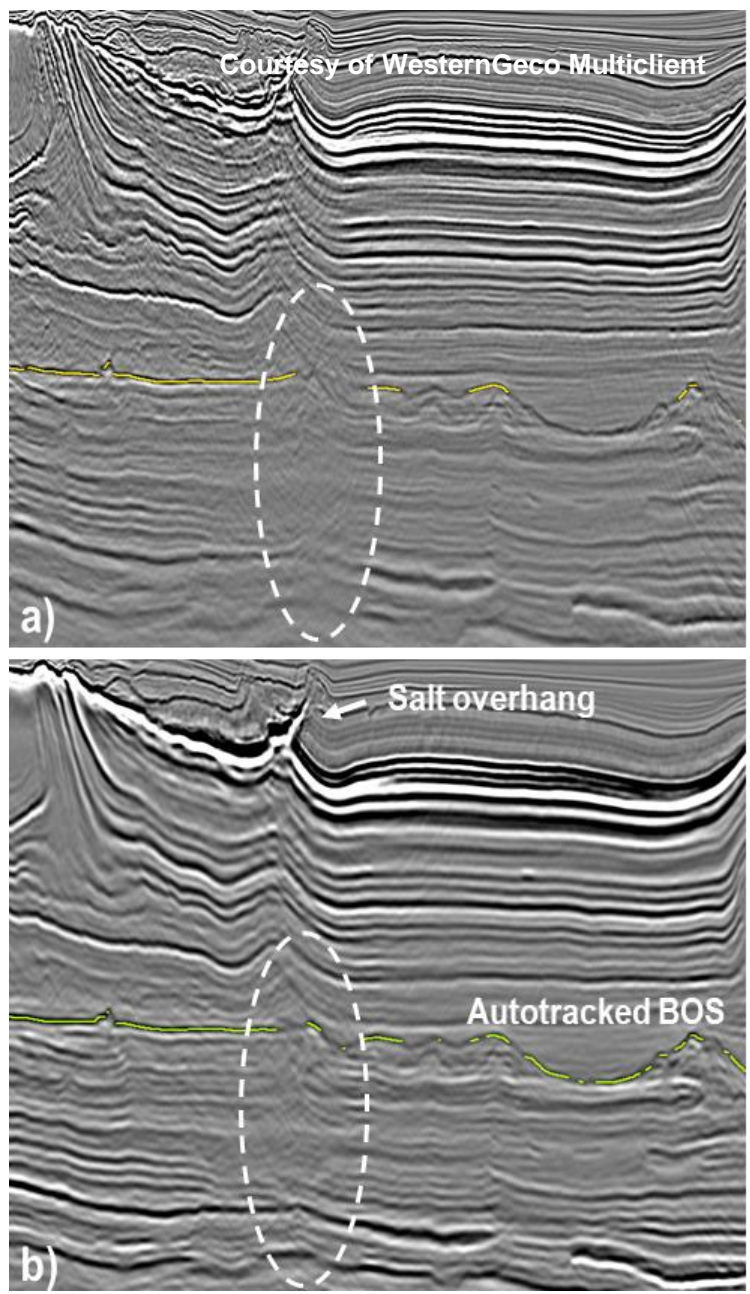

Figure 5 - Autopicking of base of salt horizon on a) legacy single azimuth image; b) final multi-azimuth processing image

\section{Acknowledgments}

We thank WesternGeco Multiclient for permission to use the datasets. We also thank the data processing team as well as Marcelo Alvarenga and José Caparica from Schlumberger's software support for the help provided in creating TecVA attributes.

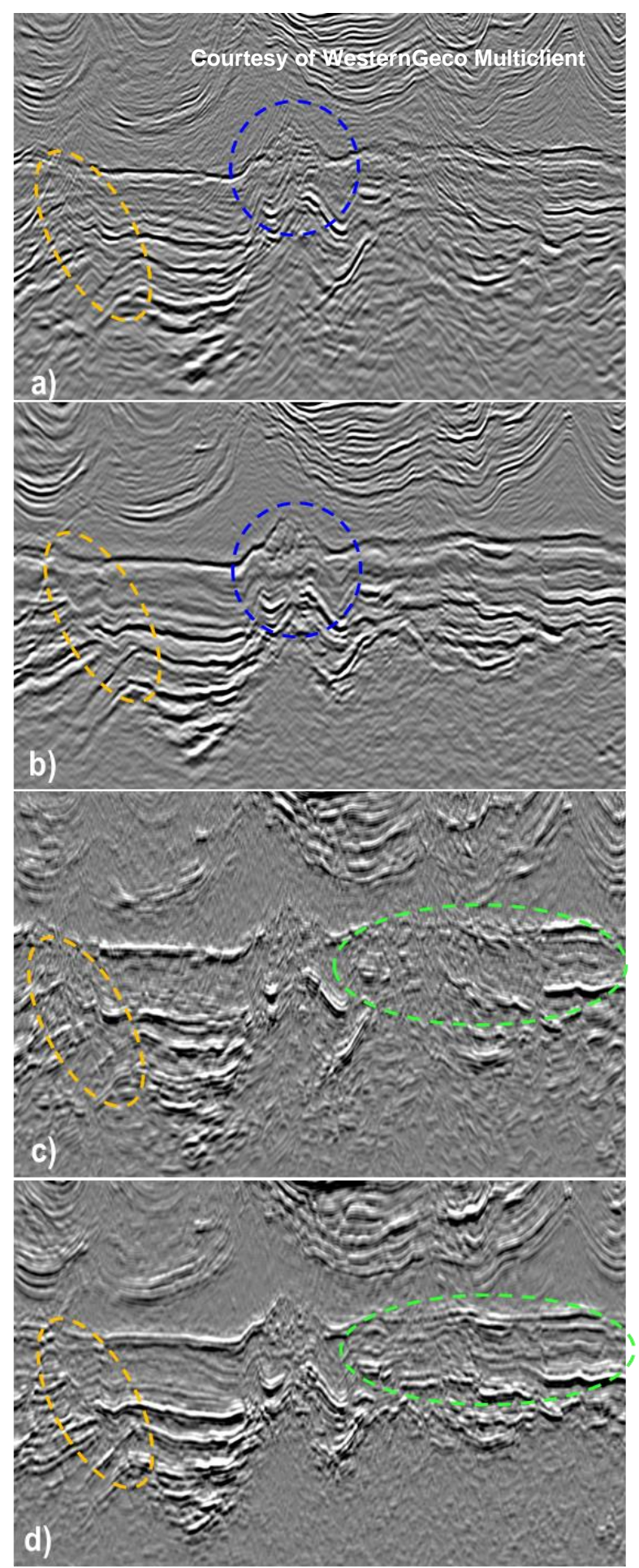

Figure 6 - Seismic section of a) legacy single azimuth image; b) final multi-azimuth RTM image; b) TecVA of legacy single azimuth image; d) TecVA of final multiazimuth RTM image 
Reducing uncertainties with MAZ imaging in pre-salt Santos Basin References

BULHÕES, I.M., AND DE AMORIN, W.N. Principio da SismoCamada elementar e sua aplicação à Técnica Volume de Amplitudes (tecVA). 9th International Congresso $f$ the Brazilian geophysicial Society \& EXPOGEOF, 2005.

CHANG, H.K., ASSINE, M.L., CORRÊA, F.S., TINEN, J.L., VIDAL, A.C. AND KOIKE, L. Sistemas petrolíferos e modelos de acumulação de hidrocarbonetos na Bacia de Santos. Revista Brasileira de Geociências, 38: 29-46, 2008.

ESPINOZA, C., SANGER, W., NICHOLS, D. AND VASQUEZ, J. Geology-Constrained Data-Driven Multiple Prediction: SEG Technical Program Expanded Abstracts, 2017.

FERNANDEZ, R. O. Bacia de Santos Sumário Geológico e Setores em Oferta. Brazil, Round 15, ANP, 19 p., 2017.

JACKSON, C.A.L., RODRIGUEZ, C.R., ROTEVATN, A., AND BELL, R.E. Geological and geophysical expression of a primary salt weld: An example from the Santos Basin, Brazil. Interpretation, v. 2, p. SM77-SM89, 2014.

LE DIAGON, F., SOLDO, J., MUNDIM, E., LEMOS, C., GARCIA, D., BARROS, A., MOLDOVEANU, N., FENWICK, A., BUNTING, T., COOKE, A. AND

CENTENO, R., First Full-Azimuth Towed-Streamer Survey Offshore Brazil - An Acquisition and Survey Design Case Study. 12th International Congress of the Brazilian Geophysical Society, 2011.

LE DIAGON, F., MOLDOVEANU, N., EL-TOUKHY, M., GRIDNEV, E., THOMPSON, J., SALINAS, L.A.

Comparison between multi-azimuth, wide-azimuth, and full-azimuth towed-streamer acquisition: a full 3D finite difference study in the Santos Basin. SEG technical program expanded abstracts, 2017.

MEISLING, K.E., COBBOLD, P.R., AND MOUNT, V.S. Segmentation of an obliquely rifted margin, Campos and Santos Basins, southeastern Brazil. AAPG Bulletin, v. 85, p. 1903-1924, 2001.

MODICA, C.J., AND BRUSH, E.R. Postrift sequence stratigraphy, paleogeography, and fill history of the deepwater Santos Basin, offshore southeast Brazil. AAPG Bulletin, v. 88, p. 923-945, 2004.

MOHRIAK, W.U., AND FAINSTEIN, R. Phanerozoic regional geology of the eastern Brazilian margin. In: D.G. Roberts and A.W. Bally, editors: Geology and tectonics: phanerozoic passive margins, cratonic basins and global tectonic maps, Vol. 1c, Elsevier, The Netherlands, p. 222283, 2012.

MOREIRA, J.L.P., MADEIRA, C., GIL, J.A., AND MACHADO, M.A.P. Bacia de Santos. Bulletin Geociencias Petrobras, v. 15, p. 531-549, 2007.

ORTIN, M., YSACCIS, R., LI, H. AND BARROS, P., Combining wave paths to improve Brazil's Presalt Image. Central Santos Basin Multi Azimuth Reimaging. Second EAGE/HGS Conference on Latin America, 2020.
RICKETT, J.E., MANEN, D.J. V., LOGANATHAN, P., AND SEYMOUR, N., Slanted-Streamer Data-Adaptive Deghosting with Local Plane Waves: Proceedings 76th EAGE Conference and Exhibition, 2014.

RODRIGUEZ, C.R., JACKSON, C.A.L., ROTEVATN, A., BELL, R.E., AND FRANCIS, M. Dual tectonic-climatic controls on salt giant deposition in the Santos Basin, offshore Brazil. Geosphere, v. 14, no. 1, p. 1-28, 2017.

SUN, D., JIAO, K., CHENG, X. AND VIGH, D., Reflectionbased waveform inversion. In SEG technical program expanded abstracts 2016 (pp. 1151-1156). Society of Exploration Geophysicists, 2016.

VYAS, M., DU, X., MOBLEY, E. AND FLETCHER, R., Methods for computing angle gathers using RTM. In 73rd EAGE Conference and Exhibition incorporating SPE EUROPEC, 2011.

WOODWARD, M., D. NICHOLS, O. ZDRAVEVA, P. WHITFIELD AND T. JOHNS, A decade of tomography: Geophysics, 73, 5, VE5-VE11, 2008 